\title{
The Effect of Artificial Ageing on the Mechanical Properties of the EN AW 2017 Alloy
}

\author{
Klara Jirounkova ${ }^{1 *}$, Jan Vozka' ${ }^{1}$ Jaromir Cais ${ }^{1}$ \\ 1 Faculty of Mechanical Engineering, Jan Evangelista Purkyne University, 40096 Usti nad Labem, Czech Republic \\ * Corresponding author's e-mail: k.jirounkova@gmail.com
}

\begin{abstract}
This paper deals with different types of artificial ageing and its effect upon the mechanical properties of an aluminium alloy. For the purposes of this research, the EN AW 2017 alloy was subjected to different types of heat treatment. These samples were subjected to different analyses. The results of hardness measurements (HB and HV) revealed the highest values of the non-heat treated sample. The static tensile stress test proved the highest ductility of the heat treated samples. Overall, the best were revealed for the sample artificially aged at $160^{\circ} \mathrm{C}$.
\end{abstract}

Keywords: aluminium alloy, heat treatment, aging, mechanical properties

\section{INTRODUCTION}

Aluminium alloys are one of the most important lightweight construction materials [8]. The $\mathrm{Al}-\mathrm{Cu}-\mathrm{Mg}-\mathrm{Si}$ type alloys are widely used in the aerospace industry due to their good combination of strength, ductility and corrosion resistance. In order to improve their mechanical properties, thermomechanical processing is usually applied $[3,2,10]$. This process consists in cold plastic deformation, solution annealing and artificial ageing (state T8) $[1,6]$. A desirable increase in the mechanical properties is due to the high dislocation density and the distribution of the strengthening particles [7]. On the other hand, the local company found cracks when bending these rods (at state T8). The occurrence of the cracks can be caused by both surface hardening by the rod manufacturing and the heat treatment $[5,4]$. The samples delivered for the analysis were cold drawn manufactured [9]. Reduction of the rods length when drawing was $4 \%$. The experiment was conducted for four sets of samples. One set of samples was not heat treated and other three sets of samples underwent three different types of heat treatment (with different artificial aging temperature). In order to compare the results of this research, an indirect compression sample was prepared for every set of samples as well.

The chemical composition of all samples were verified by means of a Q4 Tasman optical emission spectrometer. The results of this analysis and their comparison are presented in Table 1.

The heat treatment was applied on three sets of samples (each set consists of four samples, three of which were cold drawn rod manufactured and one of them was indirectly compressed). The heat treatment was conducted via Nabertherm TC 1010 electric resistance furnace.

The process of heat treatment consists in two phases. The first one was solution annealing at $490^{\circ} \mathrm{C}$ temperature followed by submerging in water at a temperature of $25^{\circ} \mathrm{C}$. The second phase was artificial ageing varying for different sets of samples $\left(140^{\circ} \mathrm{C}, 160^{\circ} \mathrm{C}\right.$ and $\left.180^{\circ} \mathrm{C}\right)$ for 600 minutes. The samples were marked as shown in Table 2.

\section{MECHANICAL PROPERTIES}

The main instrument for the comparison of different sets of samples (different temperatures of artificial ageing) involved the comparison of 
Table 1. Chemical composition of delivered samples

\begin{tabular}{|c|c|c|c|c|c|c|c|c|c|}
\hline Element & $\mathrm{Si}$ & $\mathrm{Fe}$ & $\mathrm{Cu}$ & $\mathrm{Mn}$ & $\mathrm{Mg}$ & $\mathrm{Cr}$ & $\mathrm{Zn}$ & $\mathrm{Zn}+\mathrm{Ti}$ & $\mathrm{Al}$ \\
\hline $\begin{array}{c}\text { EN AW 2017 } \\
\text { (ISO standard) }\end{array}$ & $0.2-0.8$ & $\max .0 .7$ & $3.5-4.5$ & $0.4-1.0$ & $0.4-1,0$ & $\max .0 .1$ & $\max .0 .25$ & $\max .0 .25$ & base \\
\hline results & 0.554 & 0.274 & 4.033 & 0.600 & 0.652 & 0.039 & 0.032 & 0.084 & base \\
\hline
\end{tabular}

Table 2. Marking of samples

\begin{tabular}{|c|c|c|c|c|c|}
\hline \multicolumn{2}{|c|}{ Aging Temperature } & No HT & $140^{\circ} \mathrm{C}$ & $160^{\circ} \mathrm{C}$ & $180^{\circ} \mathrm{C}$ \\
\hline \multirow{4}{*}{$\begin{array}{l}\text { Production } \\
\text { Technology }\end{array}$} & Pressed & A1 & B1 & C1 & D1 \\
\cline { 2 - 6 } & Drew & A2 & B2 & C2 & D2 \\
\cline { 2 - 6 } & Drew & A3 & B3 & C3 & D3 \\
\cline { 2 - 6 } & Drew & A4 & B4 & C4 & D4 \\
\hline
\end{tabular}

their mechanical properties. Therefore, the mechanical properties of the delivered samples were subjected to the analyses of hardness according to Brinell, Microhardness according to Vickers and static tensile test.

\section{Hardness according to Brinell}

The hardness measurements according to Brinell were performed upon the rod surface under the conditions defined by the EN ISO 6506-1 standard. This test was conducted for all drawn and pressed samples. These measurements were realised via ERNST AT250X hardness tester. The measured values (their average value after ten measurements) are reported in Table 3. These values and their comparison are graphically presented in Figure 1.

\section{Microhardness according to Vickers}

The microhardness measurements according to Vickers were performed under the conditions defined by the EN ISO 6507-1 standard upon metallographic samples $(18 \mathrm{~mm}$ diameter bars) for different heat treatments. The measurements of microhardness were focused on defying the hardness process from the sample surface

Table 3. Values of the Hardness according to Brinell

\begin{tabular}{|l|c|}
\hline \multicolumn{1}{|c|}{ Sample } & HBS $2.5 / 62.5 / 10$ \\
\hline Pressed/ without HT (A1) & 119,2 \\
\hline Drew/ without HT (A2) & 159,2 \\
\hline Pressed $/ 140^{\circ} \mathrm{C}(\mathrm{B} 1)$ & 112,0 \\
\hline Drew $/ 140^{\circ} \mathrm{C}(\mathrm{B} 2)$ & 147,9 \\
\hline Pressed $/ 160^{\circ} \mathrm{C}(\mathrm{C} 1)$ & 115,2 \\
\hline Drew $/ 160^{\circ} \mathrm{C}(\mathrm{C} 2)$ & 150,6 \\
\hline Pressed $/ 180^{\circ} \mathrm{C}(\mathrm{D} 1)$ & 111,4 \\
\hline Drew $/ 180^{\circ} \mathrm{C}(\mathrm{D} 2)$ & 148,7 \\
\hline
\end{tabular}

towards its centre in three rows turned towards each other. The first measurement was carried out at the $30 \mu \mathrm{m}$ from the surface and the last one was realised at the depth of $15 \mathrm{~mm}$ (15 indentations per row). The measurements were realised via Shimadzu HMV-2microhardness tester. The measured values (reported values are average of three values measured in the different distance from the rod surface) of the microhardness process are reported in Table 4. The microhardness of the pressed samples did not significantly change from the surface to the central part. The D1 sample showed the lowest microhardness values $(131.51 \pm 13.79 \mathrm{HV})$.

\section{Static tensile test}

The parameters of static tensile test were set in agreement with the EN ISO 6892-1 standard. The test was conducted by using a Hegewald und Peschke Inspekt 100 universal testing machine. The results of this test are presented in Table 5 . The measured values show higher values in the strength of the pressed bars compared to the drawn ones. The molded specimens exhibit lower strength values $(\mathrm{Rm})$ but higher ductility. The highest values of yield strength and contractional yield strength (Rp0.2) are shown in the drawn samples without heat treatment $-\mathrm{A}$. The highest ductility values are shown in the pressed samples, $\mathrm{A} 1$ and $\mathrm{B} 1$.

\section{MICROSCOPIC ANALYSIS}

The microstructure analysis was conducted on all samples in order to investigate the effect of heat treatment on microstructural changes. These changes were investigated via a confocal and electron microscope (with EDX detector).

\section{Confocal microscopy}

The metallographic analysis focused on the documentation of the microstructural state before and after heat treatment was realised by using Olympus LEXT OLS 3100 confocal microscope. 


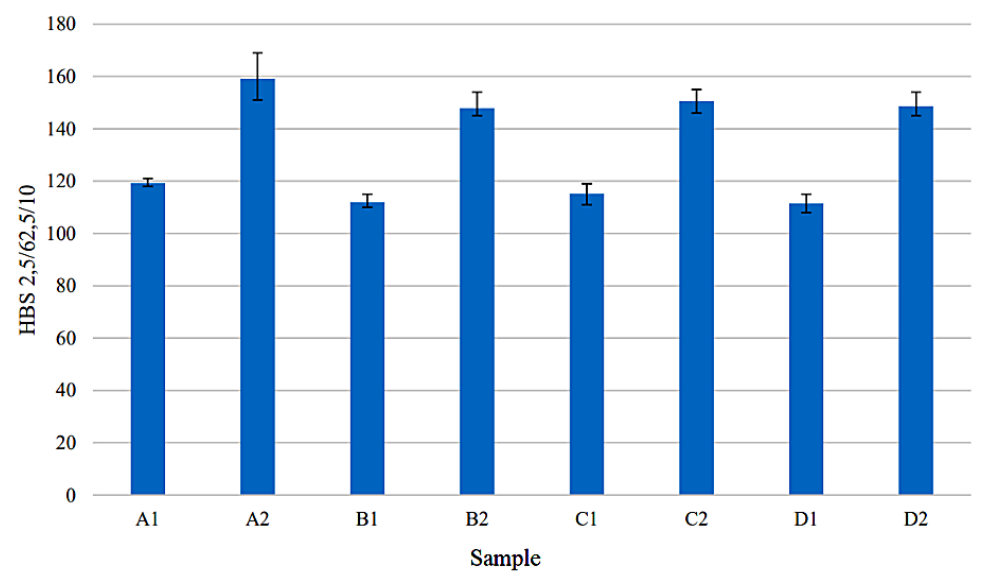

Fig. 1. Hardness values according to Brinell for different

The main aim of this analysis was to register intermetallic phases (their characteristics and morphology) occurring within their microstructure.

The A sample analysis (pressed without heat treatment) is presented in Figure 2. The microstructure of the D1 sample (pressed after solution annealing followed by artificial aging at $180^{\circ} \mathrm{C}$ temperature) is shown in Figure 3, and in detail in Figure 4.

\section{Electron microscopy}

The microstructure analysis focused on identifying intermetallic phases was performed by using a Tescan Vega 3 scanning electron microscope. In order to analyse the chemical composition of structural components, the EDX analysis was performed by using a Bruker X-Flash EDX analyser.

Apart from the intermetallic analysis, this exploration was focused on the chemical composition of the solid solution before and after being heat treated. The area of plane EDX analysis of solid solution for A1 sample is marked in Figure 6. Quantification of these results is posted in Table 6. The area of the EDX analysis of the D1 sample solid solution is marked in Figure 6. Quantification of these results is posted in Table 7.

\section{DISCUSSION}

The analysis of hardness according to Brinell and microhardness according to Vickers proved a significant difference between pressed and drawn

Table 4. Values of the Microhardness according to Vickers

\begin{tabular}{|c|c|c|c|c|c|c|c|c|}
\hline \multirow{2}{*}{$\begin{array}{c}\text { Distance } \\
{[\mu \mathrm{m}]}\end{array}$} & \multicolumn{9}{|c|}{ Sample } \\
\cline { 2 - 9 } & A1 & A2 & B1 & B2 & C1 & C2 & D1 & D2 \\
\hline 30 & 155.7 & 189.3 & 148.3 & 193.0 & 152.7 & 175.3 & 139.7 & 169.3 \\
\hline 50 & 178.7 & 191.7 & 155.0 & 193.0 & 154.3 & 176.3 & 137.3 & 166.7 \\
\hline 100 & 157.7 & 200.3 & 154.0 & 195.3 & 155.0 & 176.3 & 133.7 & 165.0 \\
\hline 150 & 157.3 & 195.7 & 150.7 & 190.3 & 159.3 & 172.0 & 131.7 & 162.0 \\
\hline 200 & 159.0 & 192.0 & 153.3 & 185.0 & 155.0 & 178.7 & 130.7 & 165.0 \\
\hline 250 & 158. & 185.3 & 150.0 & 184.0 & 151.0 & 173.0 & 135.0 & 169.0 \\
\hline 300 & 155.0 & 184.0 & 150.0 & 179.0 & 153.0 & 170.0 & 132.0 & 165.7 \\
\hline 500 & 161.0 & 184.0 & 151.3 & 174.3 & 151.7 & 170.0 & 134.3 & 164.0 \\
\hline 700 & 154.3 & 180.3 & 152.3 & 167.7 & 149.3 & 170.0 & 129.0 & 158.3 \\
\hline 1000 & 154.0 & 173.7 & 150.7 & 167.3 & 152.3 & 169.3 & 126.3 & 151.7 \\
\hline 1500 & 154.0 & 170.7 & 150.0 & 162.0 & 150.0 & 161.0 & 129.0 & 149.0 \\
\hline 2000 & 154.0 & 171.7 & 149.0 & 160.0 & 148.3 & 162.0 & 127.0 & 146.3 \\
\hline 2500 & 155.0 & 172.7 & 150.0 & 154.3 & 150.3 & 161.0 & 128.0 & 144.0 \\
\hline 3000 & 154.0 & 170.7 & 147.7 & 151.7 & 14.3 & 158.0 & 129.7 & 145.3 \\
\hline 5000 & 154.3 & 167.7 & 145.3 & 151.3 & 151.7 & 159.0 & 129.3 & 146.3 \\
\hline
\end{tabular}


Table 5. Results of Static tensile test

\begin{tabular}{|c|c|c|c|}
\hline Sample & $\mathrm{Rp}_{0,2}[\mathrm{MPa}]$ & $\mathrm{Rm}[\mathrm{MPa}]$ & $\mathrm{A}[\%]$ \\
\hline $\mathrm{A} 1$ & 311 & 458 & 20.0 \\
\hline $\mathrm{A} 2$ & 385 & 480 & 17.2 \\
\hline $\mathrm{A} 3$ & 388 & 485 & 17.7 \\
\hline $\mathrm{A} 4$ & 388 & 487 & 17.7 \\
\hline $\mathrm{B} 1$ & 276 & 417 & 18.3 \\
\hline B2 & 350 & 462 & 18.5 \\
\hline B3 & 349 & 461 & 18.5 \\
\hline B4 & 347 & 457 & 18.1 \\
\hline C1 & 280 & 413 & 17.0 \\
\hline C2 & 367 & 452 & 17.7 \\
\hline C3 & 368 & 456 & 17.7 \\
\hline C4 & 373 & 457 & 17.4 \\
\hline D1 & 275 & 356 & 13.6 \\
\hline D2 & 367 & 411 & 12.8 \\
\hline D3 & 371 & 413 & 13.0 \\
\hline D4 & 367 & 410 & 12.8 \\
\hline
\end{tabular}

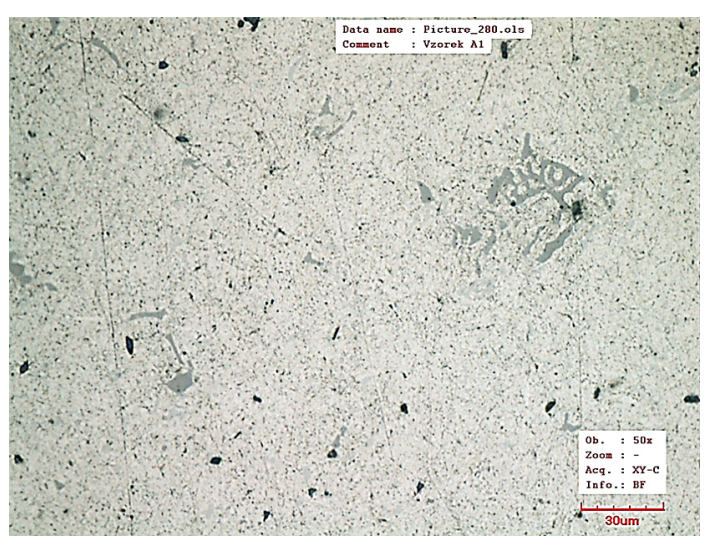

Fig. 2. Microstructure of sample A1 (confocal microscopy)

samples. Hardness according to Brinell was approximately up to $30 \%$ higher for the drawn samples (for both heat treated samples and samples without heat treatment).

The results of the microhardness process of pressed rods were not detected. Only the $180^{\circ} \mathrm{C}$ heat treated samples showed a slight decrease of microhardness up to approximately $200 \mu \mathrm{m}$ depth. On the other hand, the drawn rod samples showed a significant decrease in the microhardness process (approximately 20\%). The lowest difference between the microhardness at the surface and the centre of the rod were recorded for the drawn sample after heat treatment at $160^{\circ} \mathrm{C}$ (only 9\%).

The static tensile test revealed the highest values of the yield strength, tensile strength and ductility for the samples with no heat treatment. The

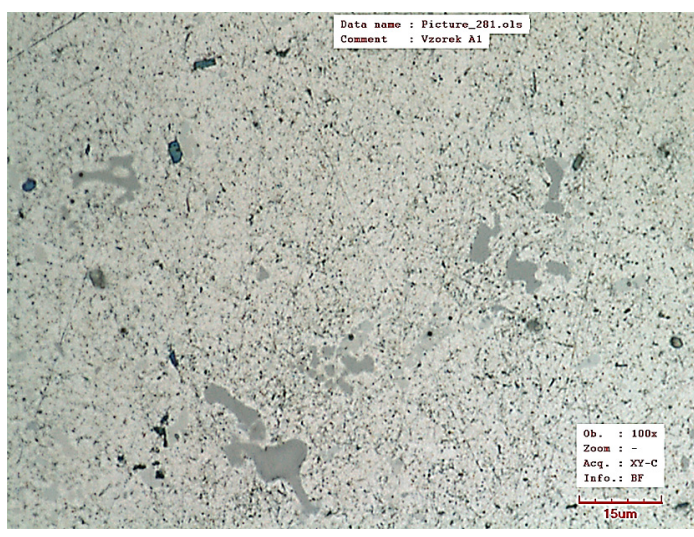

Fig. 3. Microstructure of sample A1 (confocal microscopy)

drawn samples showed up to $5 \%$ higher values of yield strength and tensile strength for the samples with no treatment. When the heat treatment being applied, this difference has increased up to $10-25 \%$. A significant difference in the ductility values was observed only for the samples with no heat treatment. The pressed samples showed approximately $12.5 \%$ higher ductility than the drawn samples. This difference drops to its minimum when the heat treatment is being applied.

The results of the microscopic analysis identified the $\mathrm{CuAl}_{2}$ intermetallic phases and other polycomponent phases based on the Al-Si-Mg, $\mathrm{Al}-\mathrm{Mg}-\mathrm{Cu}$ and $\mathrm{Al}-\mathrm{Mg}-\mathrm{Cu}-\mathrm{Si}$ type within the sample microstructure. The EDX analysis focused on the determination of the chemical composition before and after heat treatment demonstrated a higher content of copper in the solid solution caused by heat treatment.

\section{CONCLUSION}

On the basis of the conducted experiments and microstructure examination of the samples before and after heat treatment (for three different temperatures of artificial aging process), optimal parameters of heat treatment are: (i) Solution annealing - at $490^{\circ} \mathrm{C}$, held for 30 minutes, followed by submerging in water at $25^{\circ} \mathrm{C}$; (ii) Artificial ageing - at $160^{\circ} \mathrm{C}$ temperature, held for 600 mins.

These parameters of heat treatment ensure suitable microhardness process from the surface to the centre of the investigated rods (with minimal difference of microhardness values). Moreover, sufficient values of the yield strength, tensile strength and ductility were measured for these samples. The microstructure of these 


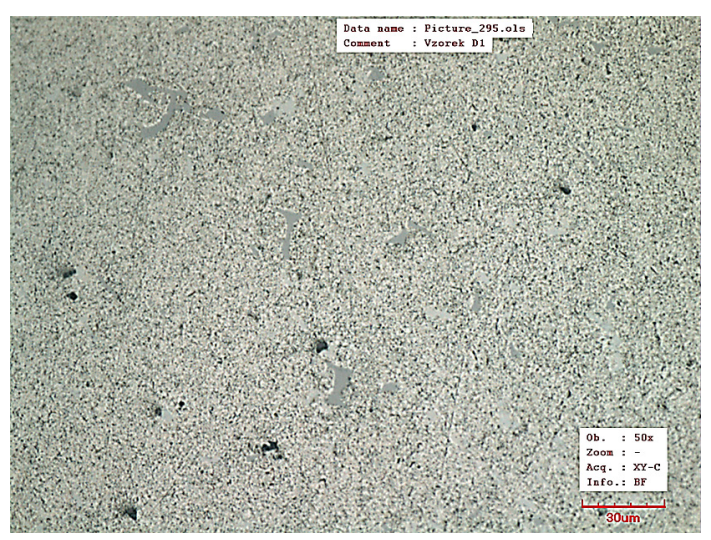

Fig. 4. Microstructure of sample D1 (confocal microscopy)

Table 6. Quantification EDX analysis results

\begin{tabular}{|l|c|c|}
\hline \multicolumn{1}{|c|}{ Element } & Content [wt. \%] & Content [at. \%] \\
\hline Aluminium & 97.59 & 98.06 \\
\hline Copper & 1.08 & 0.46 \\
\hline Magnesium & 1.33 & 1.49 \\
\hline Total & 100.00 & 100.00 \\
\hline
\end{tabular}

samples after this heat treatment regime shows a complete dissolution of $\mathrm{CuAl}_{2}$ intermetallic phases dislocated near the dendrite boundaries of solid solution. On the basis of these results, also the corrosion resistance after this heat treatment can be assumed as being improved compared to the non-heat treated state.

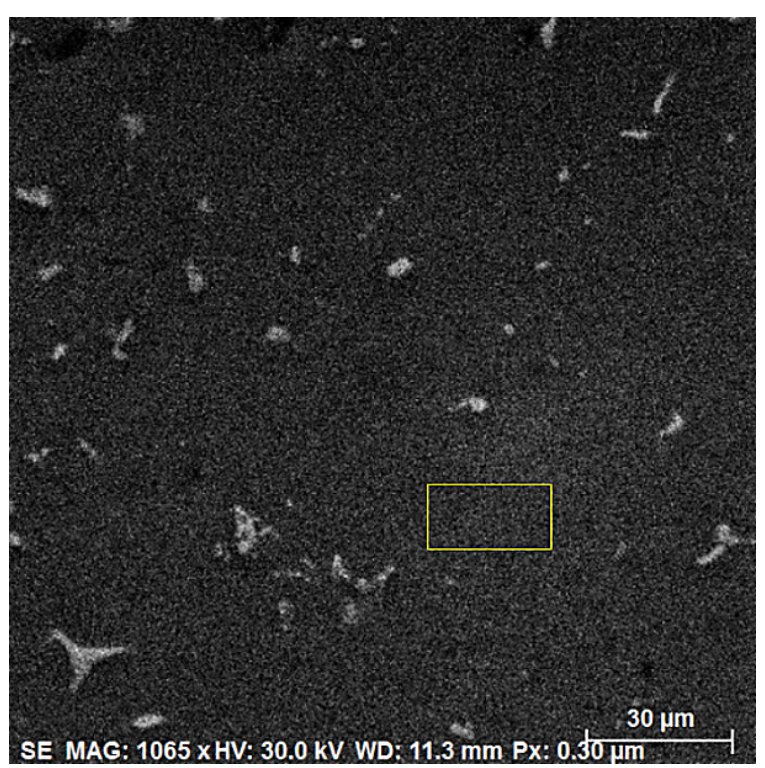

Fig. 6. Area of EDX analysis of solid solution (D1 sample)

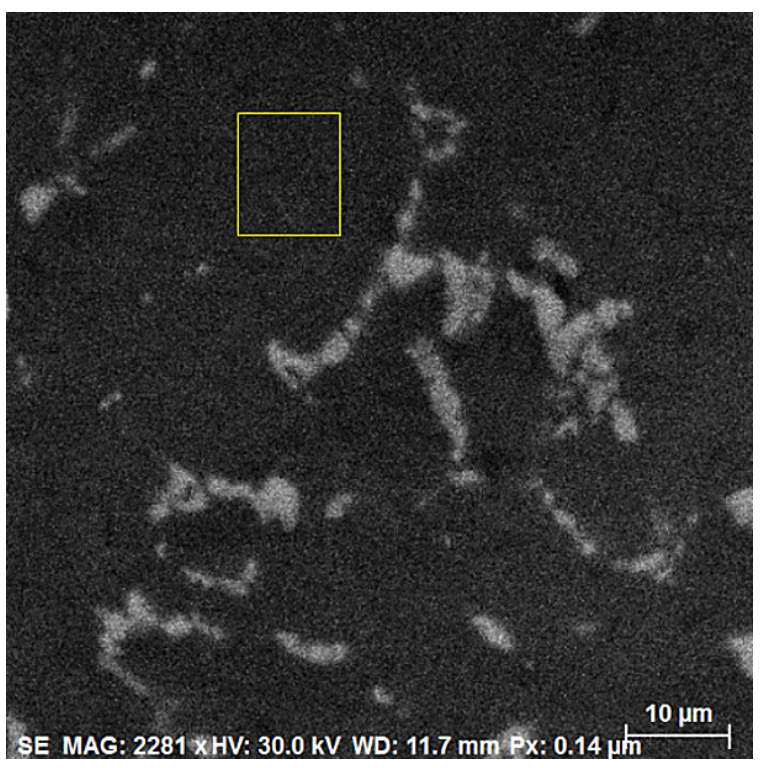

Fig. 5. Area of EDX analysis of solid solution (A1 sample)

\section{Acknowledgement}

This work was supported by SGS No. UJEP-SGS-2018-48-001-2.

\section{REFERENCES}

1. Cais J., Michna Š., Research of Influence of Heat Treatment on Microstructure and Mechanical Properties of AlSi9CuNiMn Alloy. The 9 International Seminar Advanced Manufacturing Technologies, 2015, 43-46.

2. Jiang H., Sandlöbes S., Gottstein G., \& Korte-Kerzel S., On the effect of precipitates on the cyclic deformation behavior of an $\mathrm{Al}-\mathrm{Mg}-\mathrm{Si}$ alloy. Journal of Materials Research 23(32), 2017, 4398-4410.

3. Marlaud T., Deschamps A., Bley F., Lefebvre W., Baroux B., Influence of alloy composition and heat treatment on precipitate composition in $\mathrm{Al}-\mathrm{Zn}-\mathrm{Mg}-$ $\mathrm{Cu}$ alloys. Acta Materialia 1(58), 2010, 248-260.

4. Michna Š., Cais J., Michnová L., Research of the Cause Cracking Hot-Rolled Block Made of AlMg5 Alloys. Manufacturing Technology : Journal for Science, Research and production 6(15), 2015, 614-620.

Table 7. Quantification EDX analysis results

\begin{tabular}{|l|c|c|}
\hline \multicolumn{1}{|c|}{ Element } & Content [wt. \%] & Content [at. \%] \\
\hline Aluminium & 97.46 & 98.29 \\
\hline Copper & 1.63 & 0.70 \\
\hline Magnesium & 0.91 & 1.01 \\
\hline Total & 100.00 & 100.00 \\
\hline
\end{tabular}


5. Michna S̆., Honzátko R., Cais J., The Influence of Porosity on Mechanical Properties of Cast Produced from Al-Si alloys. Manufacturing Technology, 13, 2013, 319-324.

6. Moustafa M.A., Samuel F.H., Doty H.W., Effect of solution heat treatment and additives on the microstructure of Al-Si (A413.1) automotive alloys. Journal of Materials Science, 22(38), 2003, 4507-4522.

7. Nicolas M., Deschamps A., Characterisation and modelling of precipitate evolution in an $\mathrm{Al}-\mathrm{Zn}-\mathrm{Mg}$ alloy during non-isothermal heat treatments. Acta
Materialia, 51(20), 2003, 6077-6094.

8. Santham S. K. V., Manickam D., Effect of artificial aging on mechanical properties and corrosion behaviour of a356 alloy, Proceedings of the asme international mechanical engineering congress and exposition, 14, 2017.

9. Sjölander E., Seifeddine S., The heat treatment of Al-Si-Cu-Mg casting alloys, Journal of Materials Processing Technology, 210 (10), 2010, 1249-1259.

10. Vojtěch, D., Kovové materiály, VŠCHT, Praha, 2006, pp. 186. 